Doug Campos-Outcalt, MD, MPA

University of Arizona, Phoenix

$\rightarrow$ dougco@email.arizona. edu

Dr. Campos-Outcalt is a member of the US Community Preventive Services Task Force and served on the Advisory Committee on Immunization Practices (ACIP) for 9 years -5 years as a liaison for the American Academy of Family Physicians and 4 years as a voting member.

doi: 10.12788/jfp.0153

\section{AT PRESS TIME}

The US Food and Drug Administration issued

an Emergency Use

Authorization for

third COVID-19 vaccine.

The single-dose vaccine was developed by the

Janssen Pharmaceutical

Companies of Johnson

\& Johnson. For more

information, go to

www.mdedge.com/

familymedicine

\title{
ACIP recommendations for COVID-19 vaccines-and more
}

\author{
Prioritized immunization is advised with the 2 COVID-19 \\ vaccines. A third meningococcal ACWY vaccine is now \\ the only one approved for those $>55$ years.
}

$\mathrm{T}$ he year 2020 was challenging for public health agencies and especially for the Centers for Disease Control and Prevention (CDC) and its Advisory Committee on Immunization Practices (ACIP). In a normal year, the ACIP meets in person 3 times for a total of 6 days of deliberations. In 2020, there were 10 meetings (all but 1 using Zoom) covering 14 days. Much of the time was dedicated to the COVID-19 pandemic, the vaccines being developed to prevent COVID-19, and the prioritization of those who should receive the vaccines first.

The ACIP also made recommendations for the use of influenza vaccines in the 2020-2021 season, approved the adult and pediatric immunization schedules for 2021, and approved the use of 2 new vaccines, one to protect against meningococcal meningitis and the other to prevent Ebola virus disease. The influenza recommendations were covered in the October 2020 Practice Alert, ${ }^{1}$ and the immunization schedules can be found on the CDC website at www.cdc.gov/vaccines/ schedules/hcp/index.html.

\section{COVID-19 vaccines}

Two COVID-19 vaccines have been approved for use in the United States. The first was the Pfizer-BioNTech COVID-19 vaccine, approved by the Food and Drug Administration (FDA) on December 11 and recommended for use by the ACIP on December 12. ${ }^{2}$ The second vaccine, from Moderna, was approved by the FDA on December 18 and recommended by the ACIP on December $19 .^{3}$ Both were approved by the FDA under an Emergency Use Authorization (EUA) and were approved by the ACIP for use while the EUA is in effect. Both vaccines must eventually undergo regular approval by the FDA and will be reconsidered by the ACIP regarding use in non-public health emergency conditions. A description of the EUA process and measures taken to assure efficacy and safety, before and after approval, were discussed in the September 2020 audiocast (www.mdedge. com/familymedicine/article/227333/ coronavirus-updates/coronavirus-vaccinecontenders-potential).

Both COVID-19 vaccines consist of nucleoside-modified mRNA encapsulated with lipid nanoparticles, which encode for a spike glycoprotein of SARS-CoV-2, the virus that causes COVID-19. Both vaccines require 2 doses (separated by 3 weeks for the Pfizer vaccine and 4 weeks for the Moderna vaccine) and are approved for use only in adults and older adolescents (ages $\geq 16$ years for the Pfizer vaccine and $\geq 18$ years for the Moderna vaccine) (TABLE $\mathbf{1}^{2-5}$ ).

In anticipation of vaccine shortages immediately after approval for use and a high demand for the vaccine, the ACIP developed a list of high-priority groups who should receive the vaccine in ranked order. ${ }^{6}$ States are encouraged, but not required, to follow this priority list (TABLE $2^{6}$ ).

I Caveats with usage. Both COVID-19 vaccines are very reactogenic, causing lo- 
TABLE 1

\section{How the COVID-19 vaccines compare}

\begin{tabular}{l|l|l}
\hline Details & Pfizer-BioNTech ${ }^{2,4}$ & Moderna ${ }^{3,5}$ \\
\hline Approved recipients & $\geq 16$ years & $\geq 18$ years \\
\hline Dose schedule & 2 doses, at Days 0 and 21 & 2 doses, at Days 0 and 28 \\
\hline Storage temperature & -112 to $-76^{\circ} \mathrm{F}$ & -13 to $5^{\circ} \mathrm{F}$ \\
\hline Efficacy $^{\text {a }}$ & $95 \%$ & $95 \%$ \\
\hline Clinical trial completion & $\begin{array}{l}>18,000 \\
\text { placebo vaccinated; }>18,000 \text { received }\end{array}$ & $\begin{array}{l}>13,000 \text { vaccinated; }>13,000 \text { received } \\
\text { placebo }\end{array}$ \\
\hline
\end{tabular}

against symptomatic, laboratory-confirmed COVID.

TABLE 2

COVID-19 vaccine recipient priorities ${ }^{6}$

\begin{tabular}{|c|c|c|}
\hline Phase & Groups recommended & $\begin{array}{l}\text { Total number } \\
\text { (millions) }\end{array}$ \\
\hline \multirow[t]{2}{*}{$1 \mathrm{~A}$} & Health care personnela & 21 \\
\hline & Long-term care residents & 3 \\
\hline \multirow[t]{2}{*}{ 1B } & Frontline essential workers ${ }^{b}$ & 30 \\
\hline & Those ages $\geq 75$ y & 21 \\
\hline \multirow[t]{3}{*}{ 1C } & Those ages $65-74$ y & 32 \\
\hline & Those ages $16-64$ y with high-risk medical conditions ${ }^{c}$ & 110 \\
\hline & Other essential workers ${ }^{d}$ & 57 \\
\hline 2 & All those $\geq 16$ y not included in the previous groups & All remaining \\
\hline
\end{tabular}

a All paid and unpaid individuals serving in health care settings who have the potential for direct or indirect exposure to patients or infectious materials, including body substances (blood, tissue, and specific body fluids); contaminated medical supplies, devices, and equipment; contaminated environmental surfaces; or contaminated air. These health care personnel may include, but are not limited to, emergency medical service personnel, nurses, nursing assistants, physicians, technicians, therapists, phlebotomists, pharmacists, students and trainees, contractual staff not employed by the health care facility, and individuals not directly involved in patient care but potentially exposed to infectious agents that can be transmitted among/from health care personnel and patients (eg, clerical, dietary, environmental services, laundry, security, maintenance, engineering and facilities management, administrative, billing, and volunteers).

${ }^{\mathrm{b}}$ First responders (firefighters, police); workers in education (teachers, support staff), daycare, food and agriculture, manufacturing, correctional institutions, public transit, and grocery stores; and postal workers. c Adults of any age with the following conditions are at increased risk for severe COVID-19-associated illness: cancer; chronic kidney disease; chronic obstructive pulmonary disease; heart conditions, such as heart failure, coronary artery disease, or cardiomyopathies; immunocompromised state (weakened immune system) from solid organ transplant; obesity (body mass index [BMI] $\geq 30$ but $<40$ ); severe obesity $\left(\mathrm{BMI} \geq 40 \mathrm{~kg} / \mathrm{m}^{2}\right.$ ); sickle cell disease; smoking; and type 2 diabetes.

d Those who work in transportation, food service, shelter and housing (construction), finance, information technology and communications, energy, media, legal, public safety (engineers), and water and wastewater management.

cal and systemic adverse effects that patients should be warned about (TABLE $3^{7,8}$ ). These reactions are usually mild to moderate and last 24 hours or less. Acetaminophen can alleviate these symptoms but should not be used to prevent them. In addition, both vaccines have stringent cold-storage requirements; once the vaccines are thawed, they must be used within a defined time-period.

Neither vaccine is listed as preferred.
And they are not interchangeable; both recommended doses should be completed with the same vaccine. More details about the use of these vaccines were discussed in the January 2021 audiocast (www.mdedge.com/ familymedicine/article/234239/coronavirusupdates/covid-19-vaccines-rollout-risks-andreason-still) and can be located on the CDC website (www.cdc.gov/vaccines/covid-19/ info-by-product/pfizer/reactogenicity.html; 
TABLE 3

Most common adverse effects of COVID-19 vaccines

\begin{tabular}{l|l|l}
\hline & Pfizer-BioNTech ${ }^{7}(\%)$ & Moderna $^{8}(\%)$ \\
\hline Injection site reaction, including pain & 84.1 & 92 \\
\hline Fatigue & 62.9 & 70 \\
\hline Headache & 55.1 & 64.7 \\
\hline Muscle pain & 38.3 & 61.5 \\
\hline Chills & 31.9 & 45.4 \\
\hline Joint pain & 23.6 & 46.4 \\
\hline Fever & 14.2 & 15.5 \\
\hline
\end{tabular}

www.cdc.gov/vaccines/covid-19/info-byproduct/moderna/reactogenicity.html).

Much remains unknown regarding the use of these COVID-19 vaccines:

-What is their duration of protection, and will booster doses be needed?

MenQuadfi, approved for those $\geq 2$ years including those $>55$, will likely be approved for individuals $\geq 6$ months and replace Menactra.

- Will they protect against asymptomatic infection and carrier states, and thereby prevent transmission?

- Can they be co-administered with other vaccines?

-Will they be efficacious and safe to use during pregnancy and breastfeeding?

These issues will need to be addressed before they are recommended for non-public health emergency use.

\section{Quadrivalent meningococcal conjugate vaccine (MenACWY)}

In June 2020, the ACIP added a third quadrivalent meningococcal conjugate vaccine to its recommended list of vaccines that are FDA-approved for meningococcal disease (TABLE $4^{9}$ ). The new vaccine fills a void left by the meningococcal polysaccharide vaccine (MPSV4), which is no longer marketed in the United States. MPSV4 was previously the only meningococcal vaccine approved for individuals 55 years and older.

The new vaccine, MenACWY-TT (MenQuadfi), is approved for those ages 2 years and older, including those $>55$ years. It is anticipated that MenQuadfi will, in the near future, be licensed and approved for individuals 6 months and older and will replace MenACWY-D (Menactra). (Both are manufactured by Sanofi Pasteur.)

Groups for whom a MenACWY vaccine is recommended are listed in TABLE $5 .{ }^{9} \mathrm{~A}$ full description of current, updated recommendations for the prevention of meningococcal disease is also available. ${ }^{9}$

\section{Ebola virus (EBOV) vaccine}

A vaccine to prevent Ebola virus disease (EVD) is available by special request in the United States. Recombinant vesicular stomatitis virus-based Ebola virus vaccine, abbreviated as rVSV $\triangle$ G-ZEBOV-GP (brand name, ERVBO) is manufactured by Merck and received approval by the FDA on December 19, 2019, for use in those ages 18 years and older. It is a live, attenuated vaccine.

The ACIP has recommended preexposure vaccination with $\mathrm{rVSV} \triangle \mathrm{G}-\mathrm{ZEBOV}$ GP for adults 18 years or older who are at risk of exposure to EBOV while responding to an outbreak of EVD; while working as health care personnel at a federally designated Ebola Treatment Center; or while working at biosafety-level 4 facilities. ${ }^{10}$ The vaccine is protective against just 1 of $4 \mathrm{EBOV}$ species, Zaire ebolavirus, which has been the cause of most reported EVD outbreaks, including the 2 largest EVD outbreaks in history that occurred in West Africa and the Republic of Congo.

It is estimated that EBOV outbreaks have infected more than 31,000 people and resulted in more than 12,000 deaths worldwide. ${ }^{11}$ Only 11 people infected with EBOV have been treated in the United States, all related to the 2014-2016 large outbreaks in West Africa. Nine of these cases were imported and only 1 resulted in transmission, to 2 people. ${ }^{10}$ The mammalian species that are suspected as intermediate hosts for EBOV are not present in the United States, which prevents EBOV from becoming endemic here. 
TABLE 4

Vaccines for meningococcal serogroup A, C, W, and $\mathrm{Y}^{9}$

\begin{tabular}{l|l|l|l}
\hline Product (manufacturer) & Trade name & Licensed for ages & Year licensed \\
\hline MenACWY-D (Sanofi Pasteur) & Menactra & 9 mo-55 y & 2005 \\
\hline MenACWY-CRM (GlaxoSmithKline) & Menveo & 2 mo-55 y & 2010 \\
\hline MenACWY-TT (Sanofi Pasteur) & MenQuadfi & $\geq 2$ y & 2020 \\
\hline
\end{tabular}

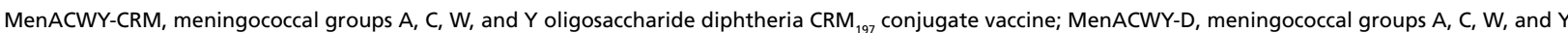
polysaccharide diphtheria toxoid conjugate vaccine; MenACWY-TT, meningococcal groups $A, C, W$, and $Y$ polysaccharide tetanus toxoid conjugate vaccine.

\section{TABLE 5}

\section{Who should receive MenACWY vaccine in the United States? $?^{9}$}

\begin{tabular}{|c|c|}
\hline Population & Dosing recommendation \\
\hline Adolescents ages $11-18$ y & $\begin{array}{l}1 \text { dose at age } 11 \text { or } 12 y \text {; booster at age } \\
16 y\end{array}$ \\
\hline $\begin{array}{l}\text { Individuals with complement component deficiency, including patients taking a } \\
\text { complement inhibitor }\end{array}$ & \multirow{3}{*}{2 dose primary series; booster every $5 \mathrm{y}^{\mathrm{a}}$} \\
\hline Individuals with functional or anatomic asplenia (including sickle cell disease) & \\
\hline Individuals with HIV infection & \\
\hline Microbiologists routinely exposed to Nisseria meningitidis & 1 dose; booster every 5 y \\
\hline Individuals at increased risk during an outbreak & $\begin{array}{l}1 \text { dose (booster if previously vaccinated } \\
\geq 5 \text { y earlier) }\end{array}$ \\
\hline $\begin{array}{l}\text { Individuals who travel to, or reside in, countries where meningococcal disease is } \\
\text { endemic or hyperendemic }\end{array}$ & $\begin{array}{l}1 \text { dose; booster if remaining at increased } \\
\text { risk at } 5 \text { y }\end{array}$ \\
\hline Unvaccinated or under-vaccinated college freshmen living in residence halls & 1 dose \\
\hline Military recruits & $\begin{array}{l}1 \text { dose; booster every } 5 \text { y on basis of } \\
\text { assignment }\end{array}$ \\
\hline
\end{tabular}

${ }^{a}$ For children $<7 \mathrm{y}$ who receive the vaccine, give the first booster at $3 \mathrm{y}$ and every $5 \mathrm{y}$ thereafter.

The rVSVAG-ZEBOV-GP vaccine was tested in a large trial in Africa during the 2014 outbreak. Its effectiveness was 100\% (95\% confidence interval, $63.5 \%-100 \%$ ). The most common adverse effects were injection site pain, swelling, and redness. Mildto-moderate systemic symptoms can occur within the first 2 days following vaccination, and include headache (37\%), fever (34\%), muscle pain $(33 \%)$, fatigue $(19 \%)$, joint pain (18\%), nausea (8\%), arthritis (5\%), rash (4\%), and sweating $(3 \%) \cdot{ }^{10}$ Data are not available to assess the safety of the vaccine during pregnancy; vaccinating pregnant women should probably be avoided unless the risk of exposure to EBOV is high.

Since the vaccine contains a live virus that causes stomatitis in animals, it is possible that the virus could be transmitted to humans and other animals through close contact. Accordingly, the CDC has published some precau- tions including, but not limited to, not donating blood and, for 6 weeks after vaccination, avoiding contact with those who are immunosuppressed..$^{10}$ The vaccine is not commercially available in the United States and must be obtained from the CDC. Information on requesting the vaccine is available at www.cdc.gov/ vhf/ebola/clinicians/vaccine/. JFP

\section{References}

1. Campos-Outcalt D. Prospects and challenges for the upcoming influenza season. J Fam Pract 2020;69:406-411.

2. Oliver SE, Gargano JW, Marin M, et al. The Advisory Committee on Immunization Practices' interim recommendation for use of Pfizer-BioNTech COVID-19 vaccine-United States, December 2020. MMWR Morb Mortal Wkly Rep. 2020;69:1922-1924.

3. Oliver SE, Gargano JW, Marin M, et al. The Advisory Committee on Immunization Practices' interim recommendation for use of Moderna COVID-19 vaccine-United States, December 2020. MMWR Morb Mortal Wkly Rep. 2021;69:1653-1656.

4. CDC. Pfizer-BioNTech COVID-19 vaccine. Accessed February 17 , 2021. www.cdc.gov/vaccines/covid-19/info-by-product/pfizer/ index.html

5. CDC. Moderna COVID-19 vaccine. Accessed February 17, 2021. CONTINUED ON PAGE 92 
www.cdc.gov/vaccines/covid-19/info-by-product/moderna/ index.html\#: : text=How\%20to\%20Store\%20the\%20Moderna\%20 COVID\%2D19\%20Vaccine\&text=Vaccine $\% 20$ may\%20be $\% 20$ stored\%20in,for\%20this\%20vaccine\%20is\%20tighter

6. Dooling K, Marin M, Wallace M, et al. The Advisory Committee on Immunization Practices' updated interim recommendation for allocation of COVID-19 Vaccine-United States, December 2020. MMWR Morb Mortal Wkly Rep. 2021;69:1657-1660.

7. FDA. Fact sheet for healthcare providers administering vaccine. [Pfizer-BioNTech]. Accessed February 17, 2021. www.fda.gov/ media/144413/download

8. FDA. Fact sheet for healthcare providers administering vaccine. [Moderna]. Accessed February 17, 2021. www.fda.gov/ media/144637/download

9. Mbaeyi SA, Bozio CH, Duffy J, et al. Meningococcal vaccination recommendations of the Advisory Committee on Immunization Practices, United States, 2020. MMWR Recomm Rep. 2020;69:1-41.

10. Choi MJ, Cossaboom CM, Whitesell AN, et al. Use of Ebola vaccine: Recommendations of the Advisory Committee on Immunization Practices-United States, 2020. MMWR Recomm Rep. 2021;70:1-12.

11. CDC. Ebola background. Accessed February 17, 2021. www.cdc gov/vaccines/acip/meetings/downloads/slides-2020-02/Ebola02-Choi-508.pdf 